\title{
DETERMINATION AND EVALUATION OF THE FACTORS OF OUTSOURCING LOGISTICS
}

\author{
Andrius Jaržemskis \\ Vilnius Gediminas Technical University, Transport Research Institute, Plytinès g. 27, \\ LT-10105 Vilnius, Lithuania. Phone: (+370 5) 2699714 \\ E-mail:andrius.j@ti.vtu.lt
}

Received 24 November 2004; accepted 4 January 2006

\begin{abstract}
This paper focuses on the determination and evaluation of the factors of logistic outsourcing. Many authors usually talk about logistics service outsourcing and its reasons and benefits as well, but if some functions of the service are not outsourced, we can not really entitle "outsourcing" as the whole service providing. In logistics activity if one or several functions are outsourced it is not always possible to entitle "logistics outsourcing". In this paper outsourcing logistics criteria are described. The results of the survey among traders in Lithuania of outsourcing logistics are presented as well.
\end{abstract}

Keywords: logistic outsourcing, warehousing, transportation.

\section{Introduction}

Most of the early papers on outsourcing logistics focus on reasons for outsourcing logistics activities and what to expect from it, whereas recently additional attention has been given to key success factors and the role of outsourcing logistics providers in supply chain management [1-4]. Differently from other researchers attention in this paper is focused on the criteria which notify outsourcing logistics and its survey.

Many authors have identified a group of basic or traditional logistical functions which is necessary for the overall quality of the distribution service package. Ballou [5], Christopher [6] and other researchers mark such operations as sales forecasting, raw materials working-process inventory, sourcing and purchasing, production planning, distribution engineering, inventory management, plant warehousing, customer service, order processing, distribution system planning, field warehousing, inbound, intra-company, and outbound transportation, distribution control as logistics functions. Responsibility for performing these functions can be shifted and shared in a variety of ways, but no function can be completely eliminated, because delivery regularity is one of the basic costumer's requirements. An organization can produce needed logistical services internally or make external purchases. Daugherty and Drög [7] in their work analyzed theoretical aspects of outsourcing logistics and the evolu- tion of outsourcing logistics which some thesis are presented in this article.

Much has been written in recent years about outsourcing logistics activities. Various terms have been introduced to describe the outsourcing phenomenon, such as third-party logistics and logistics alliances by van Laarhoven and others [8], but the "terminology is not always consistent". In some cases the term third-party logistics is used to describe outsourcing of transportation and/or warehousing. Most authors, however, refer to the use of external parties to perform functions that can encompass the entire logistics process or selected activities within that process and that have traditionally been performed within an organization.

In van Laarhoven and Sharman research [9] third party logistics was defined as "activities carried out by logistics service provider on behalf of a shipper and consisting of at least management and execution of transportation and warehousing". They mark, that in addition, other activities can be included, for example, inventory management, information related activities, such as tracking and tracing, value added activities, such as secondary assembly and installation of products, or even supply chain management. Also, the contract must contain some management, analytical or design activities, and the length of the cooperation between shipper and provider must be at least one year, to distinguish third-party logistics from traditional outsourcing of transportation and/or warehous- 
ing. It should be noted that by using this definition researchers [5] distinguish between single activity outsourcing and outsourcing of a more complex character, which is not done in most other surveys on outsourcing logistics.

The basic economic justification for any form of outsourcing is the economy of scale associated with specialization. Firms choose to specialize in performing functions associated with increasing returns. Functions with increasing costs should be evaluated regarding possible abandonment or restricted usage. Specialized service providers may be positioned to offer lower costs, improve performance quality, and reduce risk.

Logistics outsourcing is difficult to understand without logistics service parts distribution which is present in Amrahamsson and Wandel [4]. Daugherty and Drög [7] focus on five logistics parts - transportation, warehousing, order entry and processing, inventory management, and freight audit and payment. These functions represent core functions common to most firms and necessary for daily operations and show a cross-section of logistical activities.

When logistics services are purchased externally, the co-ordination of logistics activities and the availability of information may become even more critical. Therefore, data-processing and communications services provided by outside vendors may influence outsourcing decisions.

According to the presented papers we choose a paradigm that warehousing and transport are core logistics functions. In this case warehousing and transportation outsourcing are the criteria of logistics outscoring. If a company has own warehouse but outsource transportation service, it can not be logistics outsourcing. The same is if the company uses own transport means, but outsources warehouse service. In both cases one of two basic logistics functions is provided. If transportation and warehousing functions are both outsourced, we can really talk about outsourcing logistics. Outsourcing transportation and outsourcing warehousing criteria are external purchasing and nonoutsourcing criteria - self providing or ownership.

The second attention is focused on influence of logistics outsourcing level on a delivery channel. In Fujimoto paper [10] collaborative networking in a multi-stage industrial channel is presented. Outsourcing logistics provider is very well incorporated in supply chains management of manufacturers, but I try to prove this thesis in a young economic market in Lithuania.

The aim of my work was to research outsourcing logistic criteria concept and to perform the survey of outsourcing logistics in Lithuania. The basic tasks are to evaluate outsourcing level in Lithuania and to prove the impact of outsourcing logistics on delivery chan- nels. The results of the research are presented in the article as follows: Firstly, the theoretical point of logistics outsourcing criteria is selected and the point of other researchers view is analyzed as well. Secondly, the methods, results and comments of the survey of outsourcing logistics in Lithuania are presented. The conclusions follow.

\section{Method and results of the case survey in Lithuania}

A survey questionnaire was used to collect the data. The questionnaire was developed based on the information obtained from an earlier pilot study. Personal interviews with 7 firms during the pilot study helped to identify logistical trends and major concerns within those firms. The questionnaire was then sent to 3035 Lithuanian trading companies. A total of 55 or 1.8 percent returned usable questionnaires from traders companies. Respondents were asked to specify:

- annual turnover and work force;

- their own or bought warehouse service;

- their own transport dept or bought transport service;

- supply channel structure- delivery from a manufacturer directly or from a distribution terminal.

These questions were distributed to small, medium and big business companies according to the Lithuanian law.

Let's select companies which have their own warehouse - HOW; which purchase warehouse service - PWS; which have their own transport dept HOT, which purchase transport service - PTS. In the following tables and figure the results of the survey and the author's commentary are presented. Many respondents' answers show that pure outsourcing of transport or warehousing is not in all companies. Some traders used a mixed outsourcing/self-providing form. They are companies with their warehouses and own transport fleet and they outsource the mentioned logistics functions, if their own resources are not enough for trade turnover in some high sales periods. For this reason in the article a mixed form -"additional outsourcing when it's necessary" between outsourcing and non-outsourcing is used. For warehouse HOW/ PWS and for transport - HOT/PTS are selected.

The results presented in Table 1 show the dominating position of non-outsourcing in warehousing area. All small business companies select - HOW (25 percent warehouse outsourcing is additional). The same situation is found in big business area. The difference is only in warehouse capacity. Many small companies keep inventory in their offices or in twenty square meters separate rooms entitled as warehouses. Big business companies conversely have big and mod- 
ern warehouses which are used for self inventory warehousing and rent unused free space to other companies - mostly medium size. Medium business (71.9 percent) has own warehousing versus 28.1 percent of pure outsourcing warehousing.

Table 2 presents the situation in transport. In opposition to warehousing small and big business outsources transport - agreeably 60.0 and 63.6 percent. It can be explained as follows - small business has not enough finance to own transport, big business understands outsourcing advantages and purchases these activities from forwarding companies. Only medium business has 40 percent of outsourced transportation.

We can see in Table 3 that especially PTS is dominating among PWS companies. 90 percent of the companies which purchase warehouse service outsources transportation as well. These companies make 14.5 percent of the total set of the survey (Fig below). These companies can be entitled as companies with pure outsourcing logistics. The next are the companies which use mixed form -"additional outsourcing when it's necessary" (62.5 percent, Table 3).

In the figure above we see that absolutely dominating warehousing/transportation variant is $\mathrm{HOW} /$ PTS which together with HOW/HOT/PTS has 36.4 percent of the total set of survey.

In the following Table 4 supply channel structure is presented. Total 62.2 percent delivery from a manu-

Table 1. Outsourcing warehouse (in percent)

\begin{tabular}{lccc}
\hline \multirow{2}{*}{ Business size } & \multicolumn{3}{c}{ Outsourcing warehouse } \\
\cline { 2 - 4 } & HOW & HOW/PWS & PWS \\
\hline small business & 75.0 & 25.0 & 0.0 \\
\hline medium business & 56.3 & 15.6 & 28.1 \\
\hline big business & 75.0 & 25.0 & 0.0 \\
\hline Total & 61.4 & 18.2 & 20.5 \\
\hline
\end{tabular}

Table 2. Outsourcing transport (in percent)

\begin{tabular}{lccc}
\hline \multirow{2}{*}{ Business size } & \multicolumn{3}{c}{ Outsourcing transport } \\
\cline { 2 - 4 } & HOT & HOT/PTS & PTS \\
\hline small business & 20.0 & 20.0 & 60.0 \\
\hline medium business & 20.0 & 40.0 & 40.0 \\
\hline big business & 9.1 & 27.3 & 63.6 \\
\hline Total & 17.6 & 35.3 & 47.1 \\
\hline
\end{tabular}

Table 3. Outsourcing transport vs. outsourcing warehouse (in percent)

\begin{tabular}{lccc}
\hline & \multicolumn{3}{c}{ Outsourcing transport } \\
\cline { 2 - 4 } $\begin{array}{l}\text { Outsourcing } \\
\text { warehouses }\end{array}$ & HOT & HOT/PTS & PTS \\
\hline HOW & $25.9 \%$ & $33.3 \%$ & $40.8 \%$ \\
\hline HOW/PWS & $12.5 \%$ & $62.5 \%$ & $25.0 \%$ \\
\hline PWS & $0.0 \%$ & $10.0 \%$ & $90.0 \%$ \\
\hline
\end{tabular}

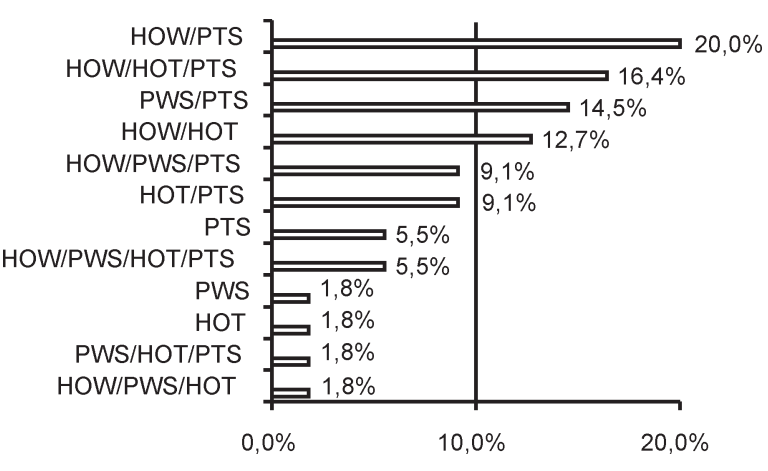

Fig. Outsourcing transportat and warehousing

Table 4. Supply channel structure (in percent)

\begin{tabular}{lcccc}
\hline $\begin{array}{l}\text { Trader use } \\
\text { delivery: }\end{array}$ & $\begin{array}{c}\text { small } \\
\text { business }\end{array}$ & $\begin{array}{c}\text { medium } \\
\text { business }\end{array}$ & $\begin{array}{c}\text { big } \\
\text { business }\end{array}$ & Total \\
\hline $\begin{array}{l}\text { from a } \\
\text { manufacturer } \\
\text { directly }\end{array}$ & 74.0 & 62.7 & 57.5 & 62.2 \\
\hline $\begin{array}{l}\text { from a } \\
\text { distribution } \\
\text { terminal }\end{array}$ & 26.0 & 37.3 & 42.5 & 37.8 \\
\hline
\end{tabular}

Table 5. Outsourcing logistics impact on supply channel structure (in percent)

\begin{tabular}{llllllll}
\hline $\begin{array}{l}\text { supply } \\
\text { channel } \\
\text { structure: }\end{array}$ & \multicolumn{2}{c}{$\begin{array}{c}\text { Outsourcing } \\
\text { warehouses }\end{array}$} & \multicolumn{2}{c}{$\begin{array}{c}\text { Outsourcing } \\
\text { transport }\end{array}$} & $\begin{array}{c}\text { Out- } \\
\text { sourcing } \\
\text { logistics }\end{array}$ \\
\cline { 2 - 7 } $\begin{array}{l}\text { HOW/ } \\
\text { PWS }\end{array}$ & PWS & HOT & $\begin{array}{c}\text { HOT/P } \\
\text { TS }\end{array}$ & PTS & $\begin{array}{c}\text { PWS/ } \\
\text { PTS }\end{array}$ \\
$\begin{array}{l}\text { manu- } \\
\text { facturer } \\
\text { directly }\end{array}$ & 56.8 & 79.4 & 69.4 & 69.3 & 65.5 & 59.4 & 66.5 \\
\hline $\begin{array}{l}\text { from a } \\
\text { distri- } \\
\text { bution } \\
\text { terminal }\end{array}$ & 43.2 & 20.6 & 30.6 & 30.7 & 34.5 & 40.6 & 33.5 \\
\hline
\end{tabular}

facturer is an indicator of the lack of supply chain management. The perspectives for its development give a tendency to bigger business of more delivery from a distribution terminal. Big business companies perform 42.5 percent of deliveries from distribution terminal.

Table 5 gives the dependence of a logistics channel on outsourcing level. 43.2 percent of deliveries (best result) is performed from a distribution terminal by HOW companies, but 40.6 percent (best result) of deliveries is performed by PTS companies. The whole outsourcing logistics or PWS/PTS gives 33.5 percent of deliveries from a manufacturer from all deliveries.

The conclusions of the presented results follow. 


\section{Conclusions}

1. The results discussed in this paper present a clear picture of the current situation of outsourcing logistics in Lithuania. We have focused on presenting an interesting subset of data and conclusions. However, it will be clear that the results presented here are only the tip of the iceberg: first, in the next paper I plan to discuss my results in more details and focus specifically on the segmentations of my database by the following criteria: physical length of a delivery channel, sorting of shipments etc. The second one is the comparison of the data. The survey was performed in two months period months before Lithuania joined the EU. The EU opens new perspectives and after 3-5 years the EU membership of Lithuania logistics according the EU expierence must give expectative change from self providing to outsourcing logistics and from direct delivery to performing of high supply chain management technologies. Today we can only hope, but there is a perfect field for successive scientific work.

2. However the presented figures permit me to formulate the following conclusions: in Lithuania before the EU membership logistics outsourcing was undeveloped. Small companies mostly have "home" style box-rooms which are entitled as "warehouses". Small companies mostly purchase transport service. Due to small turnover outsourcing does not exist in small business. Medium size business outsources more warehouses, but less transport. Their turnover is too big for "box-rooms", like in small business, but they outsource 40 percent of transport and 40 percent has own and additional outsource. Medium size business gives the best perspectives for logistics outsourcing development. Big size business according to survey results provides warehouse service itself and there is a tendency for own warehouse concept to grow. The reason for this is the membership of big business in concerns or consortiums which enterprises provide wide spectrum of business activities including manufacture, trading and logistics. This might severely frustrate the stated ambition of independent logistics providers to get more involved in supply chain management activities [8]. Transport providers have more chance because transport service is mostly outsourced in big size business companies.

3. The total outsourcing logistics in Lithuania is established in 14.5 percent of companies. A low level of outsourcing logistics is not a reason for delivery chain structure, where direct delivery from a manufacturer dominates twice (66.5 vs. 33.5). This is proved by survey which shows that the same structure of a supply channel is used by companies with established logistics outsourcing and the same by companies without it.

\section{References}

1. Kleywegt, A. J.; Papastavrou, J. D. Acceptance and dispatching policies for a distribution problem. Transportation Science, 32(2), 1998, 127-141.

2. Lemoine, W.; Dagnaes, L. Globalisation strategies and business organisation of a network of logistics service providers. International Journal of Physical Distribution \& Logistics Management, 33(3), 2003, p. 209-228.

3. Sauvage, T. The relationship between technology and logistics third-party providers. International Journal of Physical Distribution \& Logistics Management, 33(3), 2003, p. 236-253.

4. Amrahamsson, M.; Wandel, S. A model of tearing in third-party logistics with a service parts distribution case study. Transportation Science, 1(3), 1998, p. 181-194.

5. Ballou, R. H. Business Logistics management. Upper Saddle River: Prentices-Hall International Editions, 1999.

6. Christopher, M. Logistics and supply chain management. London: Financial Times \& Prentice Hall, 1998.

7. Daugherty, P. J., Drög, C. Organizational structure in divisionalized manufacturers: the potential for outsourcing logistical services. International Journal of Physical Distribution \& Logistics Management, 27(5/6), 1997, p. 337-349.

8. Laarhoven van P.; Berglund, M.; Peters, M. Third-party logistics in Europe-five years later. International Journal of Physical Distribution \& Logistics Management, 30(5), 2000, p. 425-442.

9. Laarhoven van P.; Sharman, G. Logistics alliances: the European experience. The McKinsey Quarterly, (1), 1994, p. 39-49.

10. Fujimoto, H. Collaborative networking in a multi-stage industrial channel. International Journal of Physical Distribution \& Logistics Management, 33(3), 2003, p. 229-235. 